\title{
Global evidence directing regional preventive strategies in Southeast Asia for fighting TB/HIV
}

\author{
Myo Nyein Aung ${ }^{1,2}$, Saiyud Moolphate ${ }^{3}$, Damodar Paudel ${ }^{4}$, Mangalasiri Jayathunge $\mathrm{PH}^{5}$, Duangjai \\ Duangrithi $^{6}$, Kinley Wangdi ${ }^{7}$, Thin Nyein Nyein Aung ${ }^{8}$, Thaworn Lorga ${ }^{2}$, Kazue Higuchi ${ }^{9}$ \\ ${ }^{1}$ Department of Public Health, Juntendo University Graduate School of Medicine, Tokyo, Japan \\ ${ }^{2}$ Boromarajonani College of Nursing, Nakhon Lampang, (BCNLP) Thailand \\ ${ }^{3}$ Department of Tropical Hygiene, Faculty of Tropical Medicine, Mahidol University, Thailand \\ ${ }^{4}$ Mid-western Regional Police Hospital, Nepaljunj, Nepal \\ ${ }^{5}$ School of Medicine and Dentistry, James Cook University, Queensland, Australia \\ ${ }^{6}$ School of Pharmacy, Rangsit University, Bangkok, Thailand \\ ${ }^{7}$ Phuentsholing General Hospital, G.P.O. Phuentsholing, Chhukha, Bhutan \\ ${ }^{8}$ University of Medicine, Mandalay, Myanmar \\ ${ }^{9}$ Department of Mycobacterium Reference and Research, The Research Institute of Tuberculosis, Japan
}

\begin{abstract}
Tuberculosis (TB) and human immunodeficiency virus (HIV) co-epidemics form a huge burden of disease in the Southeast Asia region. Five out of eleven nations in this region are high TB/HIV burden countries: Myanmar, Thailand, India, Indonesia and Nepal. The trends of TB incidence in these countries have been rising in recent years, in contrast to a falling global trend. Experts in the field of TB control and health service providers have been perplexed by the association of TB and HIV infections which causes a mosaic clinical presentation, a unique course with poor treatment outcomes including death. We conducted a review of contemporary evidence relating to TB/HIV control with the aims of assisting integrated health system responses in Southeast Asia and demystifying current evidence to facilitate translating it into practice.
\end{abstract}

Key words: TB/HIV; Southeast Asia; review; TB/HIV co-epidemics

J Infect Dev Ctries 2013; 7(3):191-202.

(Received 29 July 2012 - Accepted 28 November 2012)

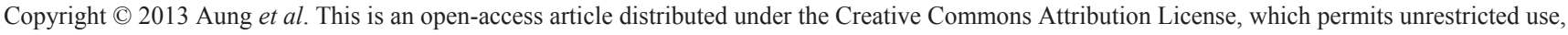
distribution, and reproduction in any medium, provided the original work is properly cited.

\section{Introduction}

Tuberculosis (TB), a centuries-old disease, causes more than a million deaths every year. After World War II, TB was well-controlled globally with TB mortality declining dramatically [1]. However, it reemerged after the 1980s following the global outbreak of the human immunodeficiency virus (HIV) infection [1]. A large number of HIV-infected individuals were rapidly killed by TB in high TB burden settings such as Africa and Thailand, as well as its neighboring countries in Southeast Asia [1-3]. The World Health Organization (WHO) declared TB a global health emergency in 1993. Afterward, global and national responses were launched progressively but heterogeneously across the countries with differing resources and health systems.
Today, TB remains a disease which is highly infectious, difficult to diagnose, and slow to treat. Its treatment and curability by multiple-combination chemotherapy is being challenged by an increase in drug resistance worldwide [2]. The technical knowledge of TB control has been hindered by the association of TB and HIV infections which causes a mosaic clinical presentation, a unique course and poor treatment outcomes including death.

In this review, both conclusive and inconclusive evidence was appraised in terms of epidemiology, diagnosis, pathophysiology, treatment, and prevention of TB/HIV co-infection. It was aimed to identify the gaps in research and integrated health system responses in Southeast Asia, catalyzing translation of contemporary evidence to practice. 


\section{TB/HIV regional epidemiology in Southeast Asia}

Globally the trend of TB burden has been falling in the last few years, but this scenario is being threatened by TB/HIV co-epidemics. The World Health Organization (WHO) estimated that in 2010 the global burden of TB cases stood at 8.8 million, while 34 million people were living with HIV and 1.1 million were TB/HIV co-infected patients [2,4]. TB/HIV coinfection caused 500,000 deaths worldwide in 2008, 380,000 deaths in 2009 and 350,000 deaths in 2010 [5]. The burden of these two diseases is highest in Africa followed by Southeast Asia. Southeast Asia is home to 3.5 million people living with HIV (PLWH) and 5 million TB patients, which represents $41 \%$ of global TB patients. Five out of eleven nations in the Southeast Asia region are high TB/HIV burden countries: India, Indonesia, Myanmar, Nepal and Thailand [6]. Neighboring countries such as Cambodia and Vietnam are also relatively high TB/HIV burden countries. The WHO estimated that HIV prevalence in Southeast Asia was $0.3 \%$, while HIV prevalence among TB patients was 5.7\% [4]. However; the burden of TB/HIV co-infection in the Southeast Asia region is heterogeneous across the 11 countries (Figure 1). PLWH residing in high TB prevalent countries experience infection and reinfection of Mycobacterium tuberculosis (M. tuberculosis) resulting in a large number of TB/HIV co-infected patients and high consequent mortality. Such incidence of $\mathrm{HIV}$-associated $\mathrm{TB}$ is highest in Myanmar, followed by Thailand, India, and Indonesia [4]. Moreover, the TB incidence in those countries has been rising in recent years, compared to a falling global trend $[3,7]$.

\section{Immunopathology of TB/HIV co-infection}

Insight into the immunopathological interrelationship between these two severe diseases has been explained by many observational and interventional studies over the last three decades $[6,8,9]$. HIV-infected individuals are more susceptible to TB infection from a new source than HIV-negative individuals. Persons co-infected with TB and HIV are 21 to 34 times more likely to develop active TB disease than persons without HIV [5]. Moreover, the incidence of severe and extra-pulmonary TB, such as TB meningitis, and death rate are higher in HIVinfected patients. The natural course of TB has been exacerbated by the HIV manipulated immunological reaction against $\mathrm{TB}$, affecting macrophage function, cytokine production, and failure to contain initial or

Figure 1. HIV prevalence (deep red line) and HIV prevalence among TB cases (blue bars) in WHO Southeast Asia Region

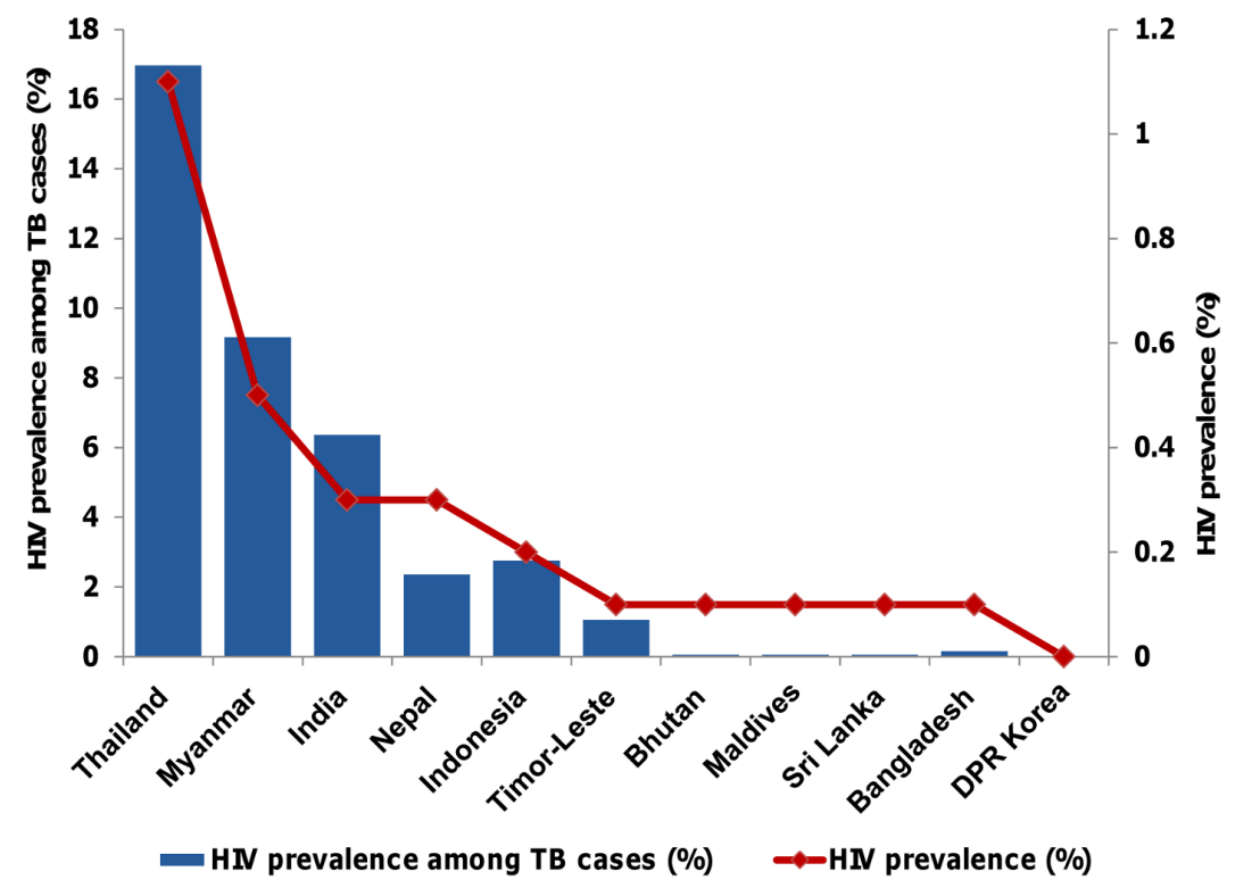

Data Source: Country reports, national AIDS programmes; Global TB Control WHO Report, 2011 Note: Figures are rounded off. Data shown are the best available estimates. Data not available for DPR Korea. 
latent $M$. tuberculosis infection and disruption of granuloma. Several hypotheses have been proposed to explain how HIV increases the risk of TB infection and how $M$. tuberculosis infection may exacerbate HIV infection, but the exact mechanism is still poorly understood [9].

Granuloma, the major hallmark of the human immune response to $\mathrm{TB}$, is a structure composed of macrophages, lymphocytes, dendritic cells, neutrophils, and sometimes fibroblasts, often with a necrotic center. It serves optimal immunologic functions to contain the $M$. tuberculosis bacilli and acts as an immune microenvironment for cellular interactions that limit $M$. tuberculosis replication. HIV co-infection disrupts the granuloma structurally and functionally [9]. The exacerbated pathology of TB in patients with HIV infection is probably due to qualitative (functional) and quantitative changes in immune response against $M$. tuberculosis, especially inside the granulomas [9].

\section{Quantitative changes}

HIV replication is increased at sites of $M$. tuberculosis infection leading to an exacerbated pathological process. Several studies that measured HIV levels in lungs, pleural cavities, and the associated macrophages observed an increased HIV replication at sites of $M$. tuberculosis infection. Nakata et al. (1997) showed that there are greater HIV p24 levels and viral loads in bronco alveolar lavage fluid (BAL) from TB-involved lungs than in BAL fluid from TB uninvolved lungs [8].

HIV induces primary or reactivated TB through the killing of $\mathrm{CD} 4^{+} \mathrm{T}$ cells within granulomas. $\mathrm{CD} 4^{+} \mathrm{T}$ cells play a major role in controlling the virulence of M. tuberculosis inside and outside the granulomas. Lawn et al. showed that the HIV-infected individuals with fewer peripheral $\mathrm{CD} 4^{+} \mathrm{T}$ cells are more prone to TB than HIV-infected individuals with relatively higher $\mathrm{CD}^{+} \mathrm{T}$ cells [10]. Furthermore, the study of Diedrich et al. reported that the reactivation of latent M. tuberculosis in cynomolgus macaques infected with simian immunodeficiency virus (SIV) is associated with early peripheral $\mathrm{T}$ cell depletion even before the rise in SIV viral load [11].

\section{Qualitative changes}

The killing mechanisms of macrophage containing M. tuberculosis are manipulated by HIV co-infection. Macrophages are major compartments of human innate immunity in containing $M$. tuberculosis infection. HIV and M. tuberculosis co-infected macrophages induce less tumor necrosis factor (TNF)dependent apoptosis than macrophages infected with only M. tuberculosis [12]. Moreover, co-infected macrophages release less TNF than macrophages infected with only $M$. tuberculosis [12]. Revealing another aspect of functional changes in macrophages, Deretic et al. showed that HIV further decreases the ability of $M$. tuberculosis-infected macrophages to acidify vesicles [13].

HIV induces functional changes in $M$. tuberculosis-specific $\mathrm{T}$ cells. Apart from killing $M$. tuberculosis-specific T cells, HIV infection induces some functional changes in those cells decreasing their ability to contain M. tuberculosis. Geldmacher et al., in their studies, observed fewer interferon-gamma (IFN- $\gamma^{+}$)-producing M. tuberculosis-specific memory $\mathrm{CD}^{+}{ }^{+} \mathrm{T}$ cells after HIV infection in individuals with latent TB [14].

Additionally, HIV exerts its adverse effects by interfering with the cell cycle [15]. The virus lowers IFN- $\boldsymbol{\gamma}$ mRNA production and therefore cellular proliferation in airways of patients with AIDS and TB as opposed to individuals with TB alone [15]. These findings were further enhanced by the observations of lower IFN- $\boldsymbol{\gamma}, \mathrm{TNF}$, and interleukin 2 (IL-2) production and cellular proliferation in M. tuberculosis-specific peripheral $\mathrm{T}$ cells in HIV-positive individuals as opposed to HIV-negative individuals with active TB [16]. Overall, the immune pathological understanding of TB/HIV co-infection has improved to explain the more severe and silent course of the two diseases in one host, but is still in the evolution phase in terms of applying improved diagnosis and treatment.

\section{Diagnosis of active TB disease in HIV-infected persons}

TB diagnosis has never been easy and straightforward, especially in HIV-infected patients, and it cannot be made by a single diagnosis test. A physician's decision, based on a clinical work-up of symptoms, chest X-ray (CXR), and sputum smear microscopic examination, triggers the TB treatment at district level hospitals within the developing setting of Southeast Asia, where culture is usually not included in the routine diagnosis algorithm [17]. Recently, the WHO-recommended TB diagnosis models were compared in HIV-infected TB suspects, in terms of cost effectiveness, to reduce the mortality within 6 months of antiretroviral therapy (ART) initiation [18]. The GeneXpert algorithm was found to be less costly than either smear-CXR or smear-CXR-culture algorithms. Culture and GeneXpert algorithms were 
more cost effective in reducing mortality than the current practice [18] (Table). This report represented a new diagnostic outline, skipping traditional diagnosis methods, which is likely to save time and resources.

\section{Algorithm for TB diagnosis in people living with HIV}

In recent years, TB diagnosis research has been conducted worldwide. However, studies done in Southeast Asia followed the diagnostic algorithm approach, which reinvented the traditional clinical parameters of ruling out active $\mathrm{TB}$ in order to start ART or to provide isoniazid preventive therapy (IPT) in a program approach. The WHO 2007 algorithm for TB diagnosis in HIV patients was evaluated in Cambodia during 2008-2009 [19]. The median time to TB treatment initiation was 5 days (interquartile range, IQR: 2-13 days), ranging from 2 days (IQR: 1-11.5 days) for extra-pulmonary TB, over 2.5 days (IQR: $1-$ 4 days) for smear-positive pulmonary TB, to 9 days (IQR: 3-17 days) for smear-negative pulmonary TB [19]. However, the sensitivity of the algorithm was very low $(58.8 \%)$ despite its inclusion of no cough or cough less than two weeks as a criterion in suspects with constitutional symptoms or abnormal chest Xray. In 2010, Cain et al. evaluated another algorithm, applying cough for any duration and other symptoms such as fever, night sweats and loss of appetite, as a way of identifying TB in PLWH (median CD4 count of 242 cells $/ \mathrm{mm}^{3}$ ) in three countries: Thailand,
Vietnam and Cambodia. The sensitivity of the algorithm was improved to $88 \%$ [20]. The authors suggested that patients lacking these symptoms could be candidates for IPT, although a small proportion, about $3 \%$, might have active TB and be undertreated [20]. These studies changed the paradigm of cough "for more than two weeks" to be cough "for any duration" when screening TB among PLWH.

\section{Current gold standard diagnostic tests}

The sputum smear microscopic examination of acid fast bacilli (AFB), discovered more than 125 years ago, still remains the mainstay bacteriological TB diagnosis test in Southeast Asia, where more than half of the reported TB incident cases were smear AFB negative [7]. Mycobacterial culture is the current gold standard diagnostic test for TB diagnosis. However, the solid culture testing system is timeconsuming, while the liquid culture testing system is expensive and not feasible in the Southeast Asia setting, except in tertiary care hospitals [21]. Adding these tests to symptoms screening and chest X-ray increases the level of TB case detection. However, smear-negative TB is highly prevalent among PLWH and atypical presentation of chest radiography and silent clinical features are not uncommon in immunecompromised patients with a very low CD4 count.

Table. The cost of three TB diagnostic algorithms for newly initiated ART among PLWH who manifest either current cough, fever, night sweats, or weight loss at the initiation of ART, South Africa, 2011 $1^{\dagger}$ [18]

\begin{tabular}{|c|c|c|c|c|c|c|c|c|c|}
\hline $\begin{array}{l}\text { Algorithm } \\
\text { components }\end{array}$ & \multicolumn{3}{|c|}{ Current practice } & \multicolumn{4}{|c|}{$\begin{array}{l}\text { WHO-recommended practice } \\
\text { with culture }\end{array}$} & \multicolumn{2}{|c|}{$\begin{array}{c}\text { WHO-recommended practice } \\
\text { with Xpert MTB/RIF }\end{array}$} \\
\hline Sputum smear* & \multirow[t]{4}{*}{+} & \multirow{4}{*}{$\begin{array}{l}- \\
+\end{array}$} & \multirow{4}{*}{ - } & \multirow[t]{4}{*}{+} & \multirow{4}{*}{$\begin{array}{l}- \\
+\end{array}$} & \multirow{4}{*}{$\begin{array}{l} \\
- \\
+\end{array}$} & \multirow{4}{*}{$\begin{array}{l}- \\
- \\
-\end{array}$} & \multirow[b]{4}{*}{+} & \multirow[b]{4}{*}{ - } \\
\hline Chest X-Ray & & & & & & & & & \\
\hline TB Culture ${ }^{\alpha}$ & & & & & & & & & \\
\hline Xpert MTB/RIF & & & & & & & & & \\
\hline TB treatment & yes & yes & no & yes & yes & yes & no & yes & no \\
\hline $\begin{array}{l}\text { Cost per TB } \\
\text { case detected }\end{array}$ & \multicolumn{3}{|c|}{$\$ 10 /$ patient } & \multicolumn{4}{|c|}{$\$ 22 /$ patient } & \multicolumn{2}{|c|}{$\$ 25 /$ patient } \\
\hline Detection rate & \multicolumn{3}{|c|}{$\begin{array}{c}70 \text { cases per } 1000 \text { patients } \\
\text { initiating ART }\end{array}$} & \multicolumn{4}{|c|}{$\begin{array}{c}86 \text { cases per } 1000 \text { patients } \\
\text { initiating ART }\end{array}$} & \multicolumn{2}{|c|}{$\begin{array}{c}78 \text { cases per } 1000 \text { patients } \\
\text { initiating ART }\end{array}$} \\
\hline $\begin{array}{l}\text { Cost for ART } \\
\text { initiation }\end{array}$ & \multicolumn{3}{|c|}{$\$ 850 /$ patient } & \multicolumn{4}{|c|}{$\$ 879$ /patient } & \multicolumn{2}{|c|}{$\$ 809$ /patient } \\
\hline
\end{tabular}

$\dagger$ ART, antiretroviral therapy; PLWH, people living with HIV; RIF, rifampicin.

* Sputum smear using 2 specimens.

${ }^{\alpha} 1$ sputum Mycobacterial culture using the automated Mycobacteria Growth Indicator Tube (MGIT).

\# Unit cost of TB diagnosis and treatment and ART costs. 
Nucleic acid amplification tests (NAATs)

NAATs are rapid TB diagnostic tests, which are faster than both smear microscopy and culture. Former generation NAATs were not sensitive enough for the effective TB screening. However, newer NAATs have increased the case detection rate of smear-negative TB among HIV-positive patients within high prevalent HIV settings. Establishment costs and human resource needs formed significant barriers, meaning that the diagnosis of TB among HIV-infected people remained a challenge in the resource-poor Southeast Asian setting. Recently, the WHO started to implement application of the GeneXpert machine and or the Xpert MTB/RIF assay (Cepheid, Sunnyvale, CA, USA). It is a cartridge-based fully automated NAAT for TB diagnosis and rifampicin resistance testing [22]. It purifies concentrates, amplifies by rapid real-time PCR assay, and identifies targeted nucleic acid sequences in the TB genome from unprocessed sputum samples and offers TB diagnosis within two hours, with minimal hands-on technical time. The sensitivity in detecting smear-negative culture-positive TB patients is $72.5 \%$ [22]. It is suitable for use in TB and HIV disease-endemic countries. All eleven countries in Southeast Asia have ordered at least one GeneXpert instrument according to the WHO monitoring of GeneXpert implementation as of 2012 [23].

Microscopic observation drug susceptibility assay (MODS)

The microscopic observation drug susceptibility assay (MODS), first evaluated in Peru, is a wellknown, low-cost and low-technical direct culture method, providing TB diagnosis and drug susceptibility results in 7 to 14 days [24]. It has been evaluated in Asian countries such as Thailand and Vietnam with variable results $[17,25]$. The TB diagnosis performance of MODS in HIV-positive patients was promising, but the sensitivity for smearnegative cases was weak at 38\% [26]. However, MODS identified TB meningitis in cerebrospinal fluid samples with a very high accuracy (positive predictive value $100 \%$ and negative predictive value $78.7 \%$ ) as well as at a low cost of 0.53 US\$ per sample [25].

\section{Serological tests}

The commercial serological tests can mislead diagnosis and increase costs. After twelve months of rigorous analysis by global experts involving evaluation of evidence from 67 studies for pulmonary TB and 27 studies for extra-pulmonary TB, the WHO issued an explicit "negative" policy recommendation to stop the use of serological tests for TB [27].

\section{Urine tests}

Detection of TB-specific biomarkers, namely Lipoarabinomannan (LAM), in the urine is an alternative diagnostic option. A newer invention, the LAM strip test offers an easy-to-perform bedside TB diagnosis for PLWH with a very low CD4 count $(<$ 200 cells $/ \mathrm{m}^{3}$ ) and most at risk of mortality [28]. Active TB cases were diagnosed at bedside within 25 minutes and at a cost of 3.5 US\$ per test. The sensitivity and specificity were $66 \%$ and $96 \%$, respectively. It could serve as a "point of care" TB diagnosis test in advanced immunocompromised patients. These performance characteristics indicated the possibility to rule in TB among PLWH with low immune status in the Southeast Asia setting. A newer sandwich immunoassay, to detect the LAM and other biomarkers in complex patients' samples, is being developed but has yet to be evaluated. Many other new tests are still in the TB diagnostic research pipeline, in the form of single tests or parts of algorithms, in the ongoing challenge of TB diagnosis.

\section{Treatment of active TB disease in HIV-infected persons}

There are three main options for the treatment of HIV-associated TB in the developing setting of Southeast Asia: 1. TB therapy, involving a combination of 4 to 6 anti-TB drugs; 2. antiretroviral therapy, with at least 3 antivirals; and 3. therapy using other drugs for prevention of opportunistic infections, such as fluconazole and co-trimoxazole preventive therapies in cases of immunodeficiency.

\section{Timing of ART and TB treatment}

The optimal timing for initiation of ART antiretroviral drugs, in relation to TB therapy, remained unclear until 2010. The pros and cons were the survival benefit and the risk of immune reconstitution inflammatory syndrome (IRIS), respectively. Afterward, three clinical trials, namely SAPiT, STRIDE and CAMELIA, conclusively confirmed the substantial survival benefit in early initiated ART [29-31]. Mortality was highest in sequential ART, i.e., starting ART after the completion of TB treatment [29]. ART initiated during TB therapy reduced the mortality rate in all three trials [29-31]. How early to begin ART during TB therapy should be judged by the level of immune deficiency according to the $\mathrm{CD} 4^{+} \mathrm{T}$ cell count of the patients. 
Among patients with $\mathrm{CD} 4^{+} \mathrm{T}$-cell counts less than 50 cells $/ \mathrm{mm}^{3}$, ART initiated two weeks after the commencement of TB treatment is beneficial in reducing AIDS-defining illnesses and death (hazard ratio $0.62,95 \% \mathrm{CI} 0.44$ to 0.86 . $\mathrm{P}=0.006$ ), and outweighs the risk for IRIS [30,31]. In a clinical trial in Cambodia, the same survival benefit of early ART was reported among patients with $\mathrm{CD}^{+} \mathrm{T}$ cell counts less than 50 cells $/ \mathrm{mm}^{3}$ and $\mathrm{CD}^{+} \mathrm{T}$ cell counts between 51-200 cells $/ \mathrm{mm}^{3}$ [31]. The goal of early ART initiation is to shorten the time that the patient has profound immunodeficiency.

ART initiated in patients after two weeks of TB treatment reduced mortality rate by $41.7 \%$, compared to those who started ART after 8 to 12 weeks. Even a brief delay made a huge difference. Recent trial results in Thailand could not find any significant difference when comparing ART initiated in patients after four weeks compared with ART started in patients at 12 weeks [32]. However, a brief delay in starting ART 4 to 8 weeks after the initiation of TB therapy in patients with $\mathrm{CD}^{+} \mathrm{T}$ cell counts more than 200 cells $/ \mathrm{mm}^{3}$ did not convey any increase in the risk of a new AIDSdefining illness or death, with a reduced risk of IRIS [29]. Moreover, immunological studies revealed that delaying the initiation of ART for up to 12 months during complete treatment of pulmonary TB among PLWH with preserved $\mathrm{CD}^{+}{ }^{+} \mathrm{T}$ cells greater than 350 cells $/ \mathrm{mm}^{3}$ may not accelerate a decline in immunologic function [33]. However, the current WHO 2010 ART guideline recommends initiating ART in TB/HIV co-infected patients irrespectively of the CD4 count.

Underpinning the implementation of this consolidated evidence was an integration of healthcare management of TB and HIV clinics which can provide a CD4 test and TB diagnosis to TB-suspected PLWH within two weeks concomitantly. Another point of view is to consider the influence of the TB site on mortality. All the studies described above recruited pulmonary $\mathrm{TB}$ patients. The incidence of extra-pulmonary TB was increasingly common among the Asian TB/HIV cohort and was associated with higher mortality [34]. A randomized control trial of HIV-associated TB meningitis in Vietnam reported a very high mortality rate $(59.8 \%$ and $55.6 \%)$ regardless of whether ART started within seven days or after two months following the start of TB treatment. The treatment outcome was not significantly different in relation to the timing of ART initiation [35]. Better therapeutic options are needed for HIV-associated extra-pulmonary TB patients, especially those with meningitis.

Despite the clinical trials results showing that survival benefit outweighed the adverse effect, the practicality of those regimens could be weakened by other factors such as common drug-drug interactions, side effects, pill burden, and the patient's compliance [6]. Anti-TB drug-induced hepatotoxicity is common. Interaction between anti-TB and highly active antiretroviral therapy (HAART) can cause failure in either treatment. Still, it is difficult to predict hepatotoxicity during TB treatment. Moreover, directly observed treatment, short-course (DOTS) strategy, the well-known compliance enhancer in a TB control program, has not been evaluated in relation to integrated TB/HIV treatment.

\section{Treatment of latent infection for preventing TB in HIV-infected persons}

Before the HIV epidemic, the Bacille CalmetteGuérin (BCG) vaccine could prevent the fatal forms of TB, namely meningitis and disseminated TB. However, there is no currently effective vaccine to prevent all forms of TB in PLWH. A newer TB vaccine is still in trial. Meanwhile, preventing active TB among PLWH, in other words, treating latent TB infection (TLTI) to prevent active TB, is an attractive alternative strategy. Currently, it is one of the constituents in the WHO's TB preventive strategies, namely the 3Is: 1 . intensive case finding; 2 . infection control; and 3, Isoniazid preventive therapy (IPT). IPT could make a difference in reducing the incidence of TB among PLWH and consequently offer a survival benefit to PLWH.

\section{TLTI or efficacy of IPT reducing TB incidence among PLWH}

IPT reduced the TB incidence among PLWH before and in the ART era. According to Cochrane's review of 12 randomized clinical trials (RCTs) in the pre-ART era [36], TB incidence in IPT-treated PLWH was $3 \%$ compared to $6 \%$ in the placebo group. Overall, IPT reduced the risk of active TB by $33 \%$ (relative risk $0.67,95 \%$ CI 0.54 to 0.85 ). Among tuberculin skin test (TST) positive PLWH, TB incidence after receiving IPT was $2 \%$ compared to $7 \%$ in the placebo group, and IPT reduced the risk of active TB by $64 \%$ (relative risk $0.36,95 \%$ CI 0.25 to 0.57). TB incidence among TST-negative HIV patients after receiving IPT was $3.8 \%$, compared to $4.5 \%$ in the placebo group. IPT reduced the risk of active TB by $14 \%$ (relative risk $0.86,95 \%$ CI 0.59 to 1.26 ) in TST- 
negative PLWH. The effect of IPT in the ART era was also reported by a prospective cohort study in a high TB burden setting of Africa: in that study, the risk of TB was drastically reduced (89\%) by IPT in PLWH receiving $\mathrm{ART}$, and $\mathrm{TB}$ incidence was lowest among those who received IPT preceding ART when compared to those who received only ART or those received only IPT [37].

\section{Efficacy of IPT offering survival benefit among PLWH}

IPT might also benefit the survival of PLWH as treating latent infection can prevent the drastic immune-deficiency triggered by active TB in HIVinfected hosts. In 2010, a study in South Africa compared the reduction of death in the ART cohorts in 12 months of follow-up and revealed a significantly longer survival time in IPT-treated than non IPTtreated groups [38]. IPT reduced the mortality of PLWH when provided with or before ART initiation [38]. Recently, a non-randomized comparative study in Thailand reported the impact of TST guided IPT on four-year follow up. TB incidence was significantly lower among PLWH attending the hospital with TSTguided IPT provision than among patients attending the hospital without it [39]. In contrast to the African report, Khawcharoenporn et al. reported that the mortality in IPT-treated and non IPT-treated cohorts were similar [39]. Those two studies were different in terms of IPT provision protocol, sample size, and the higher TB prevalence in Africa. A randomized trial in a Southeast Asian setting may give a conclusive answer.

Despite the convincing evidence cited above, IPT reached only $12 \%$ of eligible HIV patients globally in 2010 [2]. In the Southeast Asia region, only 4 of 11 countries implemented and reported the provision of IPT in 2009 [40]. Most of the countries in Southeast Asia did not include IPT in their national guidelines, according to WHO TB/HIV collaborative activities, although IPT was provided in Bhutan and Thailand [7]. One of the challenges underlying this sluggish roll-out was the difficulty in diagnosing patients with latent tuberculosis among PLWH as candidates for IPT [40].

\section{Identification of latent infection in HIV- infected persons}

To identify the HIV-infected individual who could benefit from IPT, tests to diagnose latent tuberculosis infection (LTBI) and their performance characteristics in high TB burden settings are to be determined. Since there is no gold standard for the diagnosis of LTBI, it is challenging to diagnose LTBI. Until recently, the tuberculin skin test (TST) has been the sole diagnostic for LTBI. As the TST is based on delayed-type hypersensitivity response mediated by lymphocytes, especially $\mathrm{T}$ cells after injection of a purified protein derivative (PPD), the sensitivity of the TST in the HIV-infected population is highly reduced due to immune suppression [41]. In addition, TST is also known to be confounded by prior BCG vaccination or infection of non-tuberculous mycobacterium (NTM) due to cross-reactivity of antigens, which are common in HIV-endemic areas [42].

In the last decade, interferon-gamma (IFN- $\gamma$ ) release assays (IGRAs) were developed for diagnosing LTBI. IGRAs detect the release of IFN- $\gamma$ in response to highly $M$. tuberculosis-specific antigens, such as early-secreted antigen 6 (ESAT-6) and culture filtrate protein 10 (CFP-10), which are absent from all BCG vaccine strains and most of the non-tuberculous mycobacteria (NTM) [43]. Currently, two types of IGRAs are commercially available. One of the IGRAs, QuantiFERON-TB Gold In-Tube (QFT, Cellestis Ltd., Victoria, Australia) is based on the ELISA assay and uses whole blood for antigen stimulation. QFT contains an additional $M$. tuberculosis-specific antigen, TB7.7 in addition to ESAT-6 and CFP-10. Another IGRA, T-SPOT.TB (T-SPOT, Oxford Immunotec Ltd., Abingdon, UK), is based on the Enzyme-Linked ImmunoSpot (ELISPOT) Assay and uses purified peripheral blood mononuclear cells (PBMCs) for antigen stimulation. As IGRAs stimulate antigen-specific T cells with $M$. tuberculosis specific antigens, it has been demonstrated that IGRAs have higher specificity than TST among BCG-vaccinated populations [44]. IGRAs have also been shown to have higher sensitivity than TST [44]. Since their development, IGRAs have been well accepted in many developed countries and incorporated into their TB programs. The advantages of IGRAs over TST include not only higher specificity, but avoidance of a second visit, objective test results, and booster effect. However, it would be important to note that IGRAs do have some limitations [45]. Specifically, IGRAs cannot distinguish between active TB and LTBI, or recent infection and remote infection [43]. As IGRAs measure immune responses against $M$. tuberculosis infection, as the TST does, the sensitivity of IGRAs in HIV-infected populations also decreases [46]. Although the count of $\mathrm{CD}^{+}{ }^{+} \mathrm{T}$ cells decreases with the progression of HIV infection, which could affect the sensitivity of IGRAs, it has been reported that IGRAs generally perform better among HIV-infected 
populations compared to TST [47]. Because QFT uses whole blood regardless of lymphocyte count, and TSPOT uses a certain count of PBMCs, the sensitivity of QFT is supposed to be lower than that of T-SPOT in the HIV-infected population. Furthermore, IFN- $\gamma$ response to mitogen (the positive control) in QFT was proportionate to the $\mathrm{CD} 4^{+} \mathrm{T}$ cell counts in PLWH with CD 4 counts less than 50 cells/ul. Thus fewer IFN $-\gamma^{+}-$ producing $M$. tuberculosis-specific memory $\mathrm{CD}^{+}{ }^{+} \mathrm{T}$ cells in PLWH with latent TB lead to poor sensitivity of QFT $[14,48]$. In fact, several studies have shown that the responses of T-SPOT are well retained even in HIV-infected populations, whereas those of QFT, as well as TST, decrease as the count of $\mathrm{CD}^{+}{ }^{+} \mathrm{T}$ cells declines [49]. Therefore, the best available diagnostic test for LTBI in HIV-infected populations, at present, appears to be T-SPOT; however, it is important to improve the diagnostic accuracy. More recently, it has been reported that combining TST and T-SPOT increases the diagnostic sensitivity in HIV-infected individuals [50]. Another approach to improve the sensitivity of LTBI diagnosis is to search for other potential biomarkers, such as IFN- $\gamma$ inducible protein 10 (IP-10).

Numerous studies have been undertaken since the development of IGRAs, showing them to be superior to TST in diagnosing LTBI. So far, it is not conclusive whether the use of IGRAs improves the identification of PLWH who could benefit from IPT. Further studies are needed to investigate how to optimize the performance of IGRAs in PLWH, especially in Southeast Asian settings where most of the PLWH have been BCG vaccinated and IGRAs were underutilized.

The current WHO-recommended approach for resource-limited settings is to screen PLWH for active TB using a clinical algorithm of four symptoms (current fever, cough, weight loss, and night sweats) and to provide IPT to those who are negative on screening [51]. The negative predictive value of this type of algorithm is $97.7 \%$ (95\% CI 97.4-98.0) in places with $5 \%$ TB prevalence among PLWH to rule out active TB [51]. The risk of active TB misdiagnosed as LTBI is minimal. Further studies are necessary to evaluate the implementation and impact of this guideline and its barriers in Southeast Asia.

\section{Evidence to implementation: health service delivery models}

The WHO advocated collaborative TB/HIV control activities years ago. Integrated collaboration is a challenge in most of the Southeast Asian nations. Early provision of ART in TB/HIV co-infected patients is evidence-based and supported by consistent guidelines. To translate these evidence-based guidelines into practice, countries need an adequately funded health system with a highly integrative healthcare delivery service model [52]. To initiate ART services for HIV-infected active TB patients, a onestop service that provides the basic diagnostic needs to confirm TB diagnosis, HIV tests, and CD4 counts is required. It demands a close collaboration between TB and HIV programs and health service providers. The best model for a TB/HIV health-care delivery service provides services from the national level to catchment area community hospitals. A study of three health-care service models in Malawi is worth reiterating (Figure 2) [52]: 1. in the referral based model, TB and HIV clinics refer the patients for each service; 2. in the partially integrated models, a synchronized service of TB and HIV clinics for TB/HIV patients is offered; and 3 . in the integrated models, all TB and HIV/AIDS services (HIV counselling as well as ART and TB treatment) are provided at the same clinic or the same, one-stop shop.

Current clinics in Thailand are mostly based on either model 1 or 2. The experience in Malawi has shown model 3 as the best cost-effective model that improves the patients' outcome [52]. Barriers to patient care such as a long distance to travel between HIV and TB clinics, a limited budget for ART, health care providers' delay, and a lack of a universal coverage system may possibly result in a delay in implementing the recommended guidelines for treatment. Moreover, a politically committed health system, well-funded for diagnostic and treatment services, is essential. It requires facilities for testing HIV and the CD4 count, as well as TB diagnostics and facilities for DOTS. Practically, indecisive clinical presentations, such as coughless $\mathrm{TB}$, smear-negative $\mathrm{TB}$, and high CD4 counts require a skillful physician to assess the patient and come to a clinical decision; however, this is hardly possible in catchment area clinics at the community level of developing countries.

Where the diagnostics of TB such as culture systems are lacking and where a physician to start TB treatment in query cases is not feasible, delayed referrals, under-diagnosis and consequent further transmission of $\mathrm{TB}$, resulting in poor outcome for patients, will still occur in the resource-poor setting. 
To resolve these realities in developing nations in Southeast Asia, health-care providers at the community level must be trained to proceed with a high index of TB suspicion among PLWH, to enable appropriate urgent referral for treatment with sensitive and easily applicable TB diagnostic testing, such as GeneXpert or LAM strip tests.

Recently, a multinational analysis showed that every US\$100 per capita government health expenditure was associated with a 33\% (95\% CI: $24 \%-42 \%$ ) decrease in TB/HIV mortality rates [53]. Implementing wider access to ART in a TB/HIV burden country needs huge financial resources. Access to ART is very difficult for PLWH in countries with the "out of the pocket" payment system such as the one in Myanmar. Therefore, a mechanism for mobilizing the national budget, as well as effective external support, through faster and proper entry points, is required.

\section{Research gaps in awareness studies}

TB was a well-known disease in the past and it is re-emerging as a common epidemic disease, globally. The awareness and knowledge of $\mathrm{TB}$ among the persons at most risk, such as PLWH, is very important in preventing the transmission of infection and needs immediate attention today [54] There have not been many studies assessing such awareness. A decline in TB incidence and mortality before World War I preceded the discovery of drugs and vaccines [1]. This was a historically evident example of health promotion via public awareness, which uplifted general wellbeing and reduced TB incidence. It would be beneficial to assess the awareness and knowledge of TB among PLWH and their family members, in order to deliver health education that can promote awareness of TB infection prevention.

\section{Conclusion}

We reviewed the evidence available on a global scale, with the aim of formulating a strategy for counteracting the TB/HIV disease burden in Southeast Asia. Contemporary evidence points out the benefit of early treatment and prevention of TB among PLWH. A diagnosis test for effective TB screening in PLWH is still a gap demanding further exploration in basic science and operational research. The two diseases, $\mathrm{TB}$ and HIV, can form an alliance in one patient, thereby challenging human existence and well-being. In response to this challenge, a completely integrated TB/HIV health care delivery model and local health system adjustment, allowing an integrated program of health services, is an urgent necessity.

Figure 2. Three health care delivery service models adapted from the study of Kachiza $\mathrm{C}$ et al.. $2010\lceil 52\rceil$

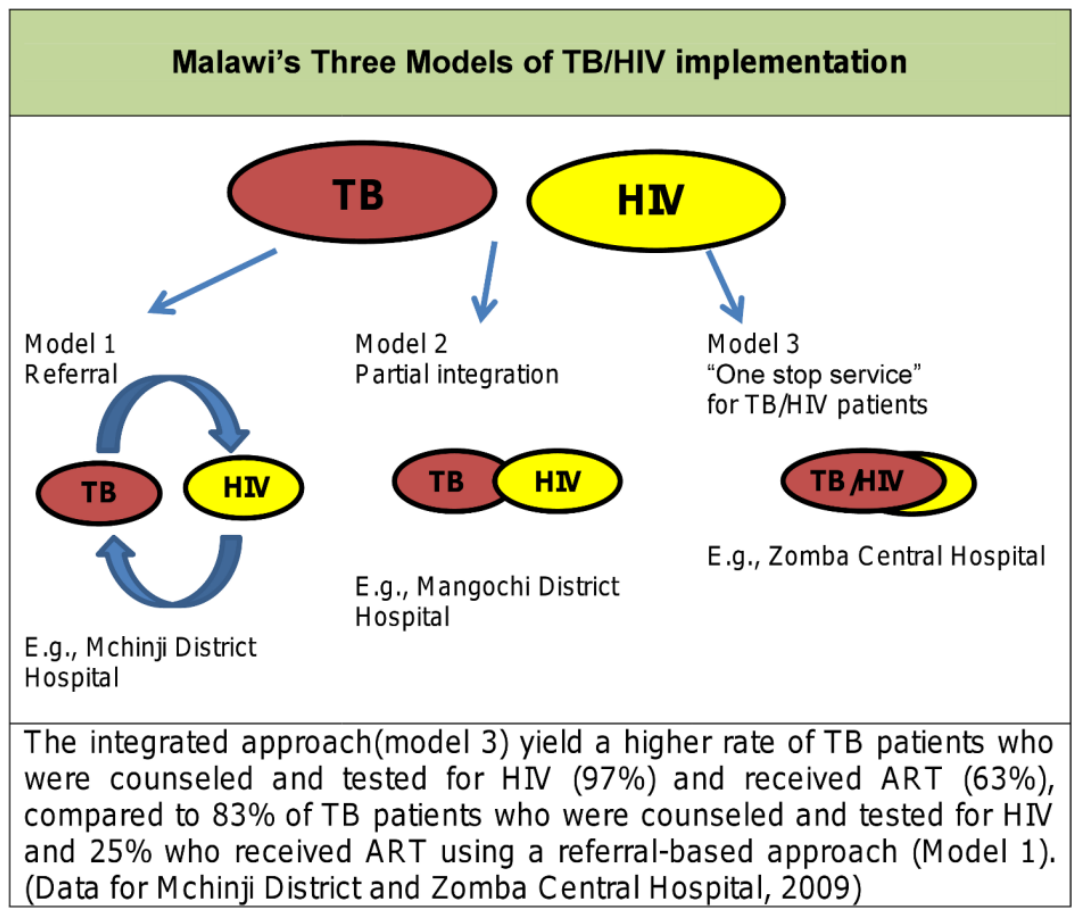




\section{Acknowledgements}

This review is dedicated to Professor Giovanni Fadda, in honour of his lifetime commitment to the study of TB. Professor Eiji Marui and Associate Professor Motoyuki Yuasa, Department of Public Health, Juntendo University Graduate School of Medicine, Tokyo, Japan are acknowledged for contributing the idea of health beyond the health to the lead author.

\section{References}

1. Lienhardt C, Glaziou P, Uplekar M, Lönnroth K, Getahun H, Raviglione M (2012) Global tuberculosis control: lessons learnt and future prospects. Nat Rev Microbiol 10: 407-416.

2. WHO (2011) Global tuberculosis control. [Available from: http://www.who.int/tb/publications/global_report/2011/gtbr11 full.pdf. Accessed 11 November 2012.

3. WHO (2011) Global HIV/AIDS response - Epidemic update and health sector progress towards Universal Access Progress Report 2011. [Available from: http://whqlibdoc.who.int/publications/2011/9789241502986 eng.pdf. Accessed 11 November 2012.

4. WHO (2011) TB/HIV in the South-East Asia Region. [Available from: http://www.searo.who.int/linkfiles/tuberculosis_status_paper tb-hiv searo 2011.pdf. Accessed 11 November 2012.

5. World Health Organization (2012) TB/HIV fact sheets: current and archieved 2009-2012. [Available from: http://www.who.int/tb/challenges/hiv/factsheets/en/index.html Accessed 11 November 2012.

6. Awodele O, Olayemi SO, Nwite JA, Adeyemo TA (2012) Investigation of the levels of oxidative stress parameters in HIV and HIV-TB co-infected patients. J Infect Dev Ctries 6: 79-85.

7. WHO. Global tuberculosis control: WHO report 2011. 2011 [Available from: http://www.who.int/tb/publications/global_report/2011/gtbr11 full.pdf. Accessed 11 November 2012.

8. $\quad$ Nakata K, Rom WN, Honda Y, Condos R, Kanegasaki S, Cao Y, Weiden M (1997) Mycobacterium tuberculosis enhances human immunodeficiency virus-1 replication in the lung. Am J Respir Crit Care Med 155: 996-1003.

9. Diedrich CR, Flynn JL (2011) HIV-1/Mycobacterium tuberculosis coinfection immunology: how does HIV-1 exacerbate tuberculosis? Infect Immun 79: 1407-1417.

10. Lawn SD, Myer L, Edwards D, Bekker LG, Wood R (2009) Short-term and long-term risk of tuberculosis associated with CD4 cell recovery during antiretroviral therapy in South Africa. AIDS 23: 1717-1725.

11. Diedrich CR, Mattila JT, Klein E, Janssen C, Phuah J, Sturgeon TJ, Montelaro RC, Lin PL, Flynn JL (2010) Reactivation of latent tuberculosis in cynomolgus macaques infected with SIV is associated with early peripheral $\mathrm{T}$ cell depletion and not virus load. PLoS One 5: e9611.

12. Patel NR, Zhu J, Tachado SD, Zhang J, Wan Z, Saukkonen J, Koziel H (2007) HIV Impairs TNF- $\alpha$ mediated macrophage apoptotic response to Mycobacterium tuberculosis. J Immunol 179: 6973-6980.

13. Deretic V, Vergne I, Chua J, Master S, Singh SB, Fazio JA, Kyei G (2004) Endosomal membrane traffic: convergence point targeted by Mycobacterium tuberculosis and HIV. Cell Microbiol 6: 999-1009.

14. Geldmacher C, Ngwenyama N, Schuetz A, Petrovas C, Reither K, Heeregrave EJ, Casazza JP, Ambrozak DR, Louder M, Ampofo W, Pollakis G, Hill B, Sanga E, Saathoff E, Maboko L, Roederer M, Paxton WA, Hoelscher M, Koup RA (2010) Preferential infection and depletion of Mycobacterium tuberculosis-specific CD4 T cells after HIV-1 infection. J Exp Med 207: 2869-2881.

15. Bonecini-Almeida Mda G, Werneck-Barroso E, Carvalho PB, de Moura CP, Andrade EF, Hafner A, Carvalho CE, Ho JL, Kritski AL, Morgado MG (1998) Functional activity of alveolar and peripheral cells in patients with human acquired immunodeficiency syndrome and pulmonary tuberculosis. Cell Immunol 190: 112-120.

16. Geldmacher C, Schuetz A, Ngwenyama N, Casazza JP, Sanga E, Saathoff E, Boehme C, Geis S, Maboko L, Singh M, Minja F, Meyerhans A, Koup RA, Hoelscher M (2008) Early depletion of Mycobacterium tuberculosis-specific T helper 1 cell responses after HIV-1 infection. J Infect Dis 198: 15901598.

17. Chaiyasirinroje B, Aung MN, Moolphate S, Kasetjaroen $Y$, Rienthong S, Rienthong D, Nampaisan O, Nedsuwan S, Sangchun W, Suriyon N, Mitarai S, Yamada N (2012) Prospective evaluation of simply modified MODS assay: an effective tool for TB diagnosis and detection of MDR-TB. Infect Drug Resist 5: 79-86.

18. Abimbola TO, Marston BJ, Date AA, Blandford JM, Sangrujee N, Wiktor SZ (2012) Cost-effectiveness of tuberculosis diagnostic strategies to reduce early mortality among persons with advanced HIV infection initiating antiretroviral therapy. J Acquir Immune Defic Syndr 60: e1e7.

19. Koole O, Thai S, Khun KE, Pe R, van Griensven J, Apers L, Van den Ende J, Mao TE, Lynen L (2011) Evaluation of the 2007 WHO guideline to improve the diagnosis of tuberculosis in ambulatory HIV-positive adults. PLoS One 6: e18502.

20. Cain KP, McCarthy KD, Heilig CM, Monkongdee $\mathrm{P}$, Tasaneeyapan T, Kanara N, Kimerling ME, Chheng P, Thai S, Sar B, Phanuphak P, Teeratakulpisarn N, Phanuphak N, Nguyen HD, Hoang TQ, Le HT, Varma JK (2010) An algorithm for tuberculosis screening and diagnosis in people with HIV. N Engl J Med 362: 707-716.

21. F. Varaine MH, V. Grouzard. Tuberculosis Practical guide for clinicians, nurses, laboratory technicians and medical auxiliaries 2008 [cited 2009 28.09]; 5th ed: Available from: http://www.refbooks.msf.org/msf_docs/en/Tuberculosis/Tube rculosis_en.pdf.

22. Boehme CC, Nabeta P, Hillemann D, Nicol MP, Shenai S, Krapp F, Allen J, Tahirli R, Blakemore R, Rustomjee R, Milovic A, Jones M, O'Brien SM, Persing DH, RueschGerdes S, Gotuzzo E, Rodrigues C, Alland D, Perkins MD (2010) Rapid molecular detection of tuberculosis and rifampin resistance. N Engl J Med 363: 1005-1015.

23. World Health organization: Tuberculosis: WHO monitoring of Xpert MTB/RIF roll-out. 2012 [Available from: http://www.stoptb.org/wg/gli/assets/documents/map/1/atlas.ht ml. Accessed 11 November 2012.

24. Moore DAJ, Evans CAW, Gilman RH, Caviedes L, Coronel J, Vivar A, Sanchez E, Piñedo Y, Saravia JC, Salazar C, Oberhelman R, Hollm-Delgado MG, LaChira D, Escombe AR, Friedland JS (2006) Microscopic-observation drug- 
susceptibility assay for the diagnosis of TB. N Engl J Med 355: 1539-1550.

25. Caws M, Ha DTM, Török E, Campbell J, Thu DDA, Chau TTH, Chau NV, Chinh NT, Farrar J (2007) Evaluation of the MODS culture technique for the diagnosis of tuberculous meningitis. PLoS One 2: e1173.

26. Ha DTM, Lan NTN, Kiet VS, Wolbers M, Hang HTT, Day J, Hien NQ, Tien NA, An PT, Anh TT, Oanh DTT, Hoa CL, Chau NTM, Hai NN, Binh NT, Ngoc LH, Phuong DT, Quyet TV, Tuyen NTB, Ha VT, Nho NT, Hoa DV, Anh PTH, Dung NH, Farrar J, Caws M (2010) Diagnosis of pulmonary tuberculosis in HIV-positive patients by microscopic observation drug susceptibility assay. J Clin Microbiol 48: 4573-4579.

27. WHO Media Center: WHO warns against the use of inaccurate blood tests for active tuberculosis. 2011 [Available from:

http:/www.who.int/mediacentre/news/releases/2011/tb 2011 0720/en/index.html. Accessed 11 November 2012.

28. Peter JG, Theron G, van Zyl-Smit R, Haripersad A, Mottay L, Kraus S, Binder A, Meldau R, Hardy A, Dheda K (2012) Diagnostic accuracy of a urine lipoarabinomannan strip-test for TB detection in HIV-infected hospitalised patients. Eur Respir J 40: 1211-1220.

29. Abdool Karim SS, Naidoo K, Grobler A, Padayatchi N, Baxter C, Gray AL, Gengiah T, Gengiah S, Naidoo A, Jithoo N, Nair G, El-Sadr WM, Friedland G, Abdool Karim Q (2011) Integration of antiretroviral therapy with tuberculosis treatment. N Engl J Med 365: 1492-1501.

30. Lancioni CL, Mahan CS, Johnson DF, Walusimbi M, Chervenak KA, Nalukwago S, Charlebois E, Havlir D, Mayanja-Kizza H, Whalen CC, Boom WH (2011) Effects of antiretroviral therapy on immune function of $\mathrm{HIV}$-infected adults with pulmonary tuberculosis and $\mathrm{CD}^{+}>350$ cells $/ \mathrm{mm}^{3}$. J Infect Dis 203: 992-1001.

31. Blanc FX, Sok T, Laureillard D, Borand L, Rekacewicz C, Nerrienet E, Madec Y, Marcy O, Chan S, Prak N, Kim C, Lak KK, Hak C, Dim B, Sin CI, Sun S, Guillard B, Sar B, Vong S, Fernandez M, Fox L, Delfraissy JF, Goldfeld AE; CAMELIA (ANRS 1295-CIPRA KH001) Study Team (2011) Earlier versus later start of antiretroviral therapy in HIV-infected adults with tuberculosis. N Engl J Med 365: 1471-1481.

32. Manosuthi W, Mankatitham W, Lueangniyomkul A, Thongyen S, Likanonsakul S, Suwanvattana P, Thawornwan U, Suntisuklappon B, Nilkamhang S, Sungkanuparph S; ; TIME Study Team (2012) Time to initiate antiretroviral therapy between 4 weeks and 12 weeks of tuberculosis treatment in HIV-infected patients: results from the TIME Study. J Acquir Immune Defic Syndr 60: 377-383.

33. Mahan CS, Walusimbi M, Johnson DF, Lancioni C, Charlebois E, Baseke J, Chervenak KA, Mugerwa RD, Havlir DV, Mayanja-Kizza $\mathrm{H}$, Whalen $\mathrm{CC}$, Boom $\mathrm{WH}$, for the Uganda-Case Western Research Collaboration (2010) Tuberculosis treatment in HIV infected Ugandans with CD4 counts $>350$ cells $/ \mathrm{mm}^{3}$ reduces immune activation with no effect on HIV load or CD4 count. PLoS One 5: e9138.

34. Kingkaew N, Sangtong B, Amnuaiphon W, Jongpaibulpatana J, Mankatittham W, Akksilp S, Sirinak C, Nateniyom S, Burapat C, Kittikraisak W, Monkongdee P, Varma JK (2009) HIV-associated extrapulmonary tuberculosis in Thailand: epidemiology and risk factors for death. Int J Infect Dis 13: $722-729$.
35. Török ME, Yen NTB, Chau TTH, Mai NTH, Phu NH, Mai PP, Dung NT, Chau NVV, Bang ND, Tien NA, Minh NH, Hien NQ, Thai PVK, Dong DT, Anh DTT, Thoa NTC, Hai NN, Lan NN, Lan NTN, Quy HT, Dung NH, Hien TT, Chinh NT, Simmons CP, de Jong M, Wolbers M, Farrar JJ (2011) Timing of initiation of antiretroviral therapy in human immunodeficiency virus (HIV)-Aassociated tuberculous meningitis. Clin Infect Dis 52: 1374-1383.

36. Akolo C, Adetifa I, Shepperd S, Volmink J (2010) Treatment of latent tuberculosis infection in HIV infected persons. Cochrane Database Syst Rev 20: CD000171.

37. Golub JE, Pronyk P, Mohapi L, Thsabangu N, Moshabela M, Struthers H, Gray GE, McIntyre JA, Chaisson RE, Martinson NA (2009) Isoniazid preventive therapy, HAART and tuberculosis risk in HIV-infected adults in South Africa: a prospective cohort. AIDS 23: 631-636.

38. Charalambous $\mathrm{S}$, Grant $\mathrm{AD}$, Innes $\mathrm{C}$, Hoffmann $\mathrm{CJ}$, Dowdeswell R, Pienaar J, Fielding KL, Churchyard GJ (2010) Association of isoniazid preventive therapy with lower early mortality in individuals on antiretroviral therapy in a workplace programme. AIDS 24: S5-S13.

39. Khawcharoenporn T, Apisarnthanarak A, Manosuthi W, Sungkanuparph S, Mundy LM (2012) Isoniazid preventive therapy and 4-year incidence of pulmonary tuberculosis among HIV-infected Thai patients. Int J Tuberc Lung Dis 16: 336-341.

40. Getahun H, Granich R, Sculier D, Gunneberg C, Blanc L, Nunn P, Raviglione M (2010) Implementation of isoniazid preventive therapy for people living with HIV worldwide: barriers and solutions. AIDS 24: S57-S65.

41. Duncan LE, Elliott AM, Hayes RJ, Hira SK, Tembo G, Mumba GT, Ebrahim SH, Quigley M, Pobee JO, McAdam KP (1995) Tuberculin sensitivity and HIV-1 status of patients attending a sexually transmitted diseases clinic in Lusaka, Zambia: a cross-sectional study. Trans R Soc Trop Med Hyg $89: 3$ 7-40.

42. Huebner RE, Schein MF, Bass JB, Jr. (1993) The tuberculin skin test. Clin Infect Dis 17: 968-975.

43. Herrera V, Perry S, Parsonnet J, Banaei N (2011) Clinical application and limitations of interferon- $\gamma$ release assays for the diagnosis of latent tuberculosis infection. Clin Infect Dis 52: 1031-1037.

44. Pai M, Zwerling A, Menzies D (2008) Systematic review: Tcell-based assays for the diagnosis of latent tuberculosis infection: an update. Ann Intern Med 149: 177-184.

45. Molicotti P, Bua A, Zanetti S (2012) Performance of QuantiFERON TB in a student population at low risk of tuberculosis. J Infect Dev Ctries 6: 100-101.

46. Stephan C, Wolf $T$, Goetsch U, Bellinger O, Nisius G, Oremek G, Rakus Z, Gottschalk R, Stark S, Brodt HR, Staszewski S (2008) Comparing QuantiFERON-tuberculosis gold, T-SPOT tuberculosis and tuberculin skin test in HIVinfected individuals from a low prevalence tuberculosis country. AIDS 22: 2471-2479.

47. Karam F, Mbow F, Fletcher H, Senghor CS, Coulibaly KD, LeFevre AM, Ngom Gueye NF, Dieye T, Sow PS, Mboup S, Lienhardt C (2008) Sensitivity of IFN-gamma release assay to detect latent tuberculosis infection is retained in HIV-infected patients but dependent on HIV/AIDS progression. PLoS One 3: e1441.

48. Fujita A, Ajisawa A, Harada N, Higuchi K, Mori T (2011) Performance of a whole-blood interferon-gamma release 
assay with Mycobacterium RD1-specific antigens among HIV-infected persons. Clin Dev Immunol 2011:325295.

49. Leidl L, Mayanja-Kizza H, Sotgiu G, Baseke J, Ernst M, Hirsch C, Goletti D, Toossi Z, Lange C (2010) Relationship of immunodiagnostic assays for tuberculosis and numbers of circulating $\mathrm{CD}^{+} \mathrm{T}$-cells in HIV infection. Eur Respir J 35: 619-626.

50. Elzi L, Steffen I, Furrer H, Fehr J, Cavassini M, Hirschel B, Hoffmann M, Bernasconi E, Bassetti S, Battegay M (2011) Improved sensitivity of an interferon-gamma release assay (TSPOT.TB ${ }^{\mathrm{TM}}$ ) in combination with tuberculin skin test for the diagnosis of latent tuberculosis in the presence of HIV coinfection. BMC Infect Dis 11: 319 .

51. WHO. Guidelines for intensified tuberculosis case-finding and isoniazid preventive therapy for people living with HIV in resource-constrained setting. WHO Library Cataloguing-inPublication Data; 2011 [Available from: http://whqlibdoc.who.int/publications/2011/9789241500708 eng.pdf. Accessed 11 November 2012.

52. Kachiza C, Msiska T, Kaonga E, Moodie C, Wandwalo E, Kellerman S, Suarez P. Management Science for Health: What is the best model of TB/HIV service delivery? Experience from Malawi. the International AIDS Conference Vienna, Austria 2010.

53. Au-Yeung C, Kanters S, Ding E, Glaziou P, Anema A, Cooper CL, Montaner JS, Hogg RS, Mills EJ (2011) Tuberculosis mortality in HIV-infected individuals: a crossnational systematic assessment. Clin Epidemiol 3: 21-29.
54. Kiefer EM, Shao T, Carrasquillo O, Nabeta P, Seas C (2009) Knowledge and attitudes of tuberculosis management in San Juan de Lurigancho district of Lima, Peru. J Infect Dev Ctries 3: $783-788$.

\section{Corresponding author}

Dr. Myo Nyein Aung

Department of Public Health, Juntendo University School of Medicine

Hongo 2-1-1, Bunkyo-ku, Tokyo, 113-8421, Japan

Telephone: 81-3-5802-1049; Fax: 81-3-3814-0305

Email: myo@juntendo.ac.jp

or

Research Co-ordinating Unit

Boromarajonani College of Nursing Nakhon Lampang

268 Parkam Road

Tambol Hauwieng, Muang District

Lampang, 52000, Thailand

Telephone: +66 5422 6254; Fax: +66 54225020

Email: dr.myonyeinaung@gmail.com

Conflict of interests: No conflict of interests is declared. 